\title{
ANALYTICAL FRAMEWORK ON CREDIT RISKS FOR FINANCING SMALL AND MEDIUM-SIZED ENTERPRISES IN ASIA
}

\author{
Naoyuki Yoshino and Farhad Taghizadeh-Hesary*
}

\begin{abstract}
Small and medium-sized enterprises (SMEs) account for the major share of employment and dominate the Asian economies. These economies are often characterized as having bank-dominated financial systems and underdeveloped capital markets, in particular venture capital. Hence, offering new methods for financing SMEs is crucial. Hometown investment trust funds are a form of financial intermediation that was started recently and has since been adopted as a national strategy in Japan. In the present paper, the authors explain the importance of SMEs in Asia and describe hometown investment trust funds. They then provide a scheme for credit rating of SMEs, employing two statistical analysis techniques, principal component analysis and cluster analysis to analyse the credit risks of a sample of Asian SMEs by using their financial variables. This comprehensive and efficient method would enable banks, to group their SME customers based on their financial health, adjust interest rates on loans and set lending ceilings for each group. Moreover, this method is applicable to hometown investment trust funds around the world.
\end{abstract}

JEL Classification: G21, G23, G24, G32.

Key words: SME credit rating, SME financing, hometown investment trust fund.

\section{INTRODUCTION}

Small and medium-sized enterprises (SMEs) are the backbone of the economies in Asia. Over the period 2007-2012, they accounted for 98 per cent of all

Naoyuki Yoshino, PhD, Dean, Asian Development Bank Institute (ADBI), Professor Emeritus, Keio University, Japan (e-mail: nyoshino@adbi.org); and Farhad Taghizadeh-Hesary, PhD, Assistant Professor of Economics, Keio University, and Research Assistant to the Dean, Asian Development Bank Institute (ADBI), Japan (e-mail: farhadth@gmail.com, farhadth@z3.keio.jp). 
enterprises and 38 per cent of the gross domestic product (GDP) on average and employed 66 per cent of the national labour force (statistics in this paragraph from $A D B, 2014)$. They also play a significant role in trade. Thirty per cent of total export value was accounted for by SMEs in Asia on average during the above-cited period. In China, SMEs accounted for 41.5 per cent of total export value in 2012, up 6.8 per cent year-on-year, while in Thailand, they accounted for 28.8 per cent of total export value, growing 3.7 per cent year-on-year. SMEs that are part of global supply chains have the potential to promote international trade and mobilize domestic demand.

Owing to the significance of SMEs to Asian national economies, it is important to find ways to provide them with stable finance. Asian economies are often characterized as having bank-dominated financial systems and capital markets that are not well developed, particularly in the area of venture capital. Consequently, banks are the main source of financing. Although the soundness of the banking system has improved significantly since the 1996 Asian financial crisis, banks have been cautious about lending to SMEs, even though such enterprises account for a large share of economic activity. Start-up companies, in particular, are finding it increasingly difficult to borrow money from banks because of strict Basel capital requirements. Riskier SMEs also face difficulty in borrowing money from banks (Yoshino, 2012). Hence, an efficient credit rating scheme that rates SMEs based on their financial health would help banks lend money to SMEs in a more rational way, while at the same time reduce their risk.

Various credit-rating indices, such as Standard and Poor's, rate large enterprises. By looking at a large enterprise's credit rating, banks can decide to lend them up to a certain amount. However, for SMEs, the issue is more complicated as there are no comparable ratings. The obstacles for setting up an SME credit rating facility are lack of data and difficulties in accessing the data to an authentic SME database. Nevertheless, there is a useful model in Japan. In a government-supported project, 52 credit guarantee corporations collected data from Japanese SMEs. These data are stored at a private corporation called the Credit Risk Database, which contains data from 14.4 million SMEs, including default data from 3.3 million corporations and sole proprietors. If similar systems could be established in other parts of Asia to accumulate and analyze credit risk data, and to accurately measure the credit risk of each SME, then banks and other financial institutions could use it to categorize their SME customers based on their financial health. SMEs would also benefit as they could raise funds from banks more easily and gain access to the debt market by securitizing their claims. Having a centralized SME database, such as the Credit Risk Database, is needed in other Asian countries and could be the long-run target for governments. In the short run, there are a number of available databases that can be used for credit rating. For example, the financial statements of SME 
customers of governmental and private institutions could be used for credit rating of bank customers or the extensive databases of SMEs held by tax bureaux of the ministries of finance could be used as a database for the credit rating of SMEs.

In addition to banks, the creation of regional funds (or hometown investment trust funds) will help promote lending to start-up companies and riskier borrowers, such as SMEs. Selling these regional trust funds through branch offices of regional banks, post offices, credit associations and large banks will open up additional sources for SMEs to raise funds.

In the present paper, section II contains a description of the importance of SMEs and their difficulties in raising money. In section III, the advantages of preparing a complete SME database in each country is explained. This is followed by a discussion on an alternative way to provide stable financing for SMEs in Asia (hometown investment trust funds). In section IV, the authors propose a way of establishing SMEs' credit ratings using statistical techniques and financial ratios. This takes into account the characteristics of SMEs, including leverage, liquidity, profitability, coverage and activity. The method can be used by banks around the world to do the following: group SMEs based on their financial health; adjust interest rates on loans; and set lending ceilings for each group. Moreover, this method is applicable for hometown investment trust funds. Section $V$ contains concluding remarks.

\section{IMPORTANCE OF SMALL AND MEDIUM-SIZED ENTERPRISES AND THEIR DIFFICULTIES TO RAISE FUNDS}

\section{Bank-dominated financial systems and the economic importance of small and medium-sized enterprises in Asia}

Figure 1 shows the size of the equity and bond markets and bank loans in Asia.

As indicated in figure 1, bank loans comprise the main share of the financial market in most Asian economies, and capital markets are not well developed in most parts of the continent. This means that banks are the main source of SME financing.

Regarding the importance of SMEs in Asia, according to a survey conducted by the Asian Development Bank (ADB) (2014) on 14 countries from the five ADB regions: (a) Kazakhstan (Central Asia); (b) China and the Republic of Korea (East Asia); (c) Bangladesh, India, and Sri Lanka (South Asia); (d) Cambodia, Indonesia, Malaysia, the Philippines, Thailand, and Viet Nam (South-East Asia); and (e) Papua New Guinea and Solomon Islands (Pacific), SMEs, together with microenterprises, account for more than 90 per cent of total enterprises in each country. 
Figure 1. Size of financial markets in Asia

Equity, bonds, and bank loans, as shares of total

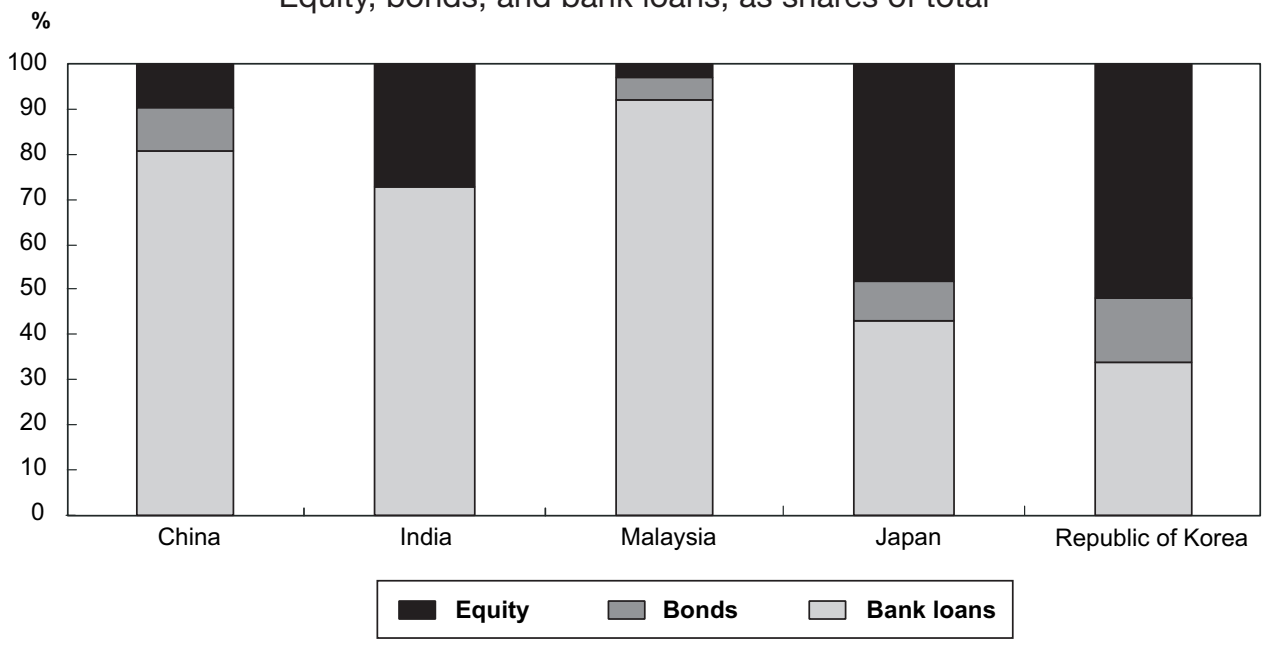

Source: Shigesuke Kashiwagi, Nomura Holdings Inc., FSA Financial Research Center International Conference, Tokyo, Japan (February 2011).

Figure 2. Small and medium-sized enterprises contribution to gross domestic product

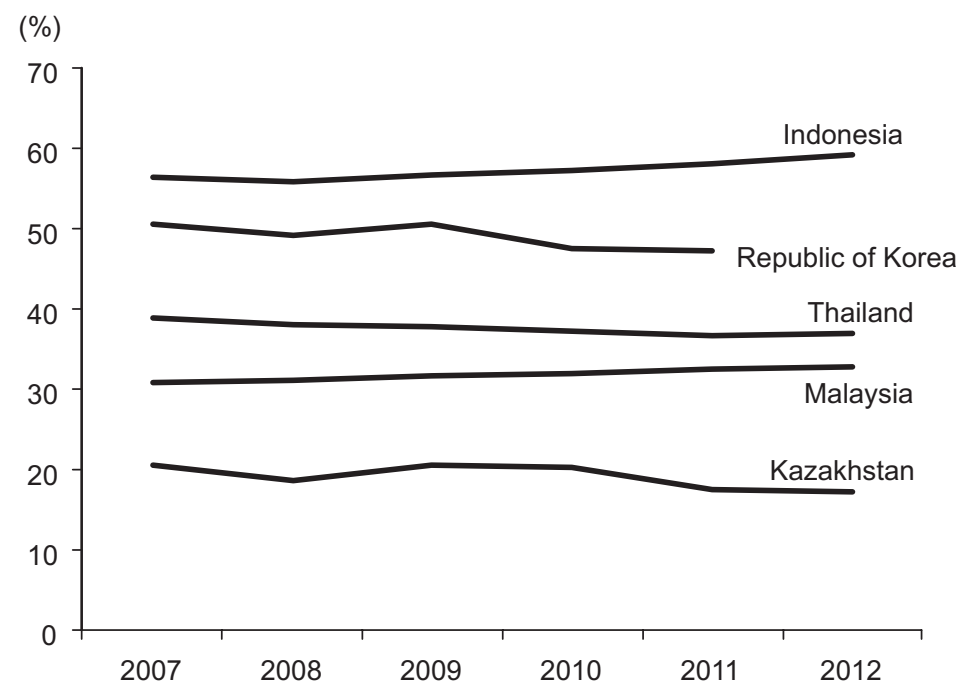

Source: $\quad$ ADB (2014); Asia SME Finance Monitor 2013.

Note: $\quad$ Republic of Korea SME contribution to gross value added in manufacturing. 
SMEs, including microenterprises, contributed to 59.1 per cent of nominal gross domestic product (GDP) in Indonesia in 2012, a figure that is gradually increasing (figure 2). SMEs and microenterprises in Thailand contributed to 37.0 per cent of nominal GDP in 2012, and in Malaysia, 32.7 per cent of real GDP in the same year. Thailand targeted an increase of the SME contribution to GDP to 40 per cent or more in its country strategy of 2012. In Kazakhstan, the nominal GDP of SMEs tended to increase but their contribution to GDP decreased over the period 2010-2012, and was 17.3 per cent in 2012.

The extent of employment by SMEs varies by country (figure 3). The share of SME employees to total employment ranged between 28.0 per cent (Kazakhstan) and 97.2 per cent (Indonesia) in 2012.

Figure 3. Employment by small and medium-sized enterprises

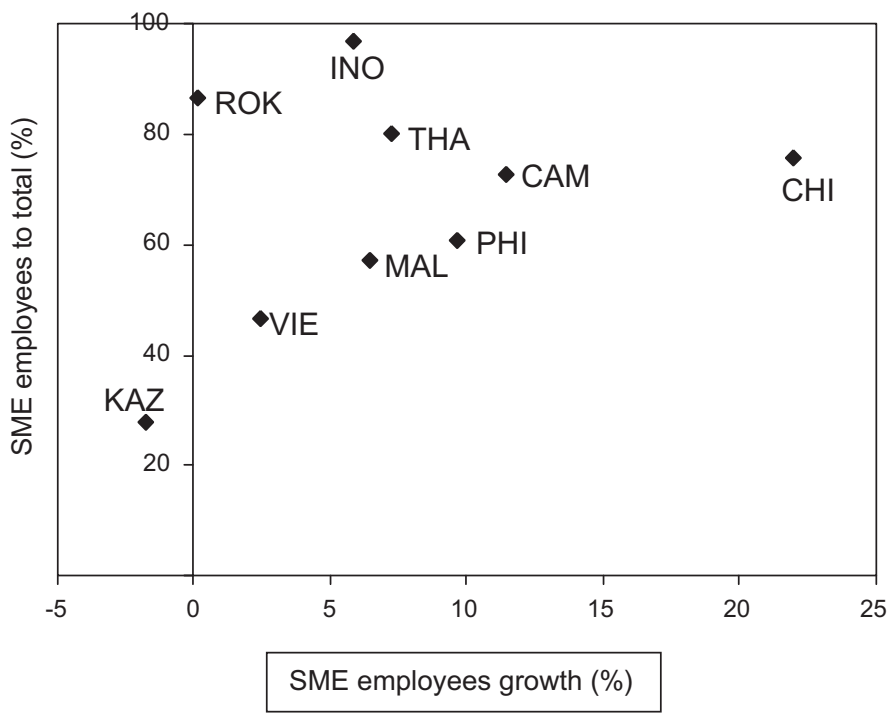

Source: $\quad$ ADB, Asia SME Finance Monitor 2013 (Manila, 2014).

Notes: $\quad \mathrm{CAM}=$ Cambodia $, \mathrm{CHI}=\mathrm{China}, \mathrm{INO}=$ Indonesia, $\mathrm{KAZ}=$ Kazakhstan, $\mathrm{ROK}=$ Republic of Korea, MAL = Malaysia, $\mathrm{PHI}=$ Philippines, $\mathrm{THA}=$ Thailand, VIE = Viet Nam.

$\mathrm{SME}=$ small and medium-sized enterprise.

Data as of 2012 in China, Indonesia, Kazakhstan, Malaysia, Thailand and Viet Nam.

Data as of 2011 in Cambodia, Republic of Korea, and the Philippines. 


\section{Small and medium-sized enterprises face difficulties to raise funds}

In comparison to large enterprises, SMEs find it more difficult to raise funds. This is because banks are reluctant to lend to them, even though these enterprises account for a large share of the economic activity in their respective countries.

Figure 4 shows the results of survey on access to funding conducted by the Bank of Japan. The two lines show how difficult or how easy it is to raise money from the markets. The thick line shows the difficulty faced by small enterprises and the thin line shows the same for the large enterprises. Data points below zero indicate that companies are finding it difficult to raise money from banks or the capital markets. Small enterprises appear to be finding it more difficult to raise money in comparison with large firms.

Figure 4. Access to financing by small and medium-sized enterprises and large firms in Japan

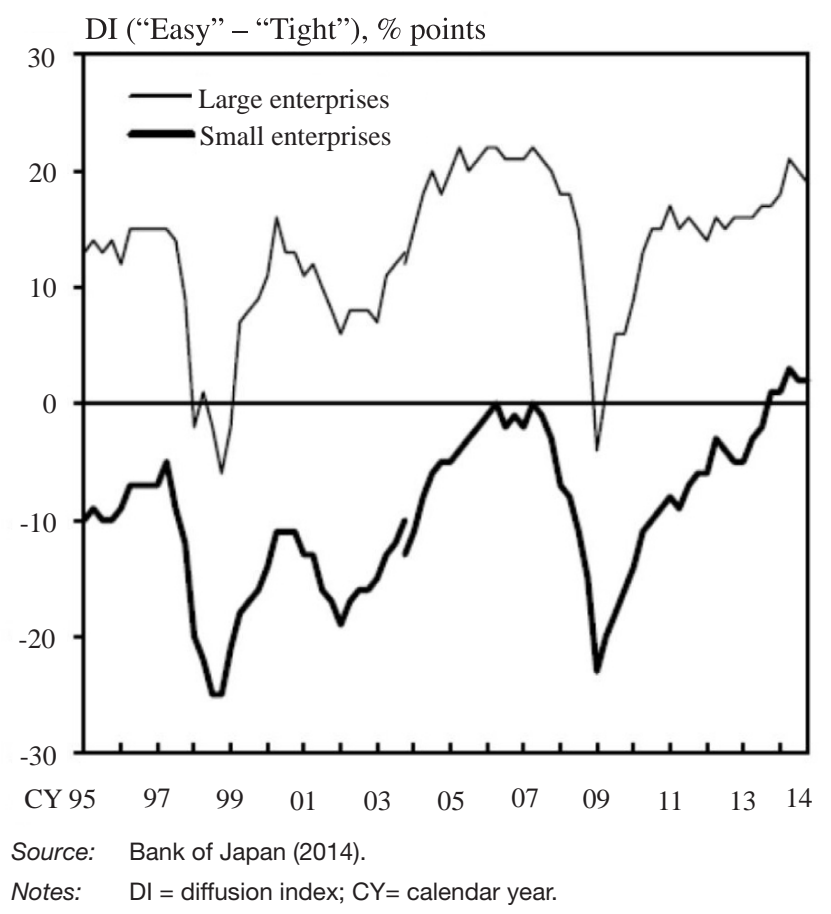




\section{SMALL AND MEDIUM-SIZED ENTERPRISE DATABASE AND STABLE FINANCE}

Considering the importance of SMEs to many dimensions of Asian economic activity, further efforts need to be made to offer them access to finance. Their financial and non-financial accounts are often difficult to assess. The Credit Risk Database in Japan, however, is being used to rate SMEs based on financial and non-financial data. Extensive data on SMEs were collected for the Database and then used to rate SMEs based on statistical analysis.

\section{Database provided by the Credit Risk Database}

The Credit Risk Database was founded in March 2001 as a membership organization to collect financial and non-financial data, including default information, on SMEs. It began as a voluntary association consisting of 52 credit guarantee corporations in Japan. The Database was established with the objective to help streamline the process for obtaining SME financing and make it more efficient by assessing business conditions based on data and measuring credit risks related to SME financing.

As its membership and data collection expanded, the Credit Risk Database became the source of data on SMEs. In April 2005, it obtained corporate status as a limited liability intermediate corporation and officially became the CRD Association. In June 2009, its status changed to a general incorporated association, as a result of the enforcement of the act on general incorporated associations and general incorporated foundations. The CRD Association collects financial data on SMEs from its members, namely credit guarantee corporations throughout Japan and government-affiliated or private financial institutions involved in SME business. The Association provides members with assessments of SMEs' business situations through a credit risk measurement model, which is based on the large amount of collected data (CRD website). ${ }^{1}$

The Credit Risk Database covers SMEs exclusively. As of March 2010, it included data on more than 50 per cent of the SMEs in Japan, covering more than 14 million corporations and about 1.7 million sole proprietors, making it by far the largest database for SMEs in Japan. The database for enterprises in default covered $3,289,000$ corporations and sole proprietors. Before the Credit Risk Database was formally established, the Government of Japan invested 1.3 billion Japanese yen ( $¥)$ $(\$ 12,000,000)$ from the supplementary budgets for fiscal years 1999 and 2000 to

www.crd-office.net. 
finance the setting up of the Credit Risk Database computer system and other operational costs. The Association provides sample data and statistical information, as well as scoring services. Members of the CRD Association provide financial/ non-financial data and default information on SMEs with whom members have relationships (the names of SMEs are encoded so that they cannot be specified) to the Database, which, in turn, returns to members a variety of services by utilizing the accumulated data (figure 5).

\section{Figure 5. Structure of Credit Risk Database}
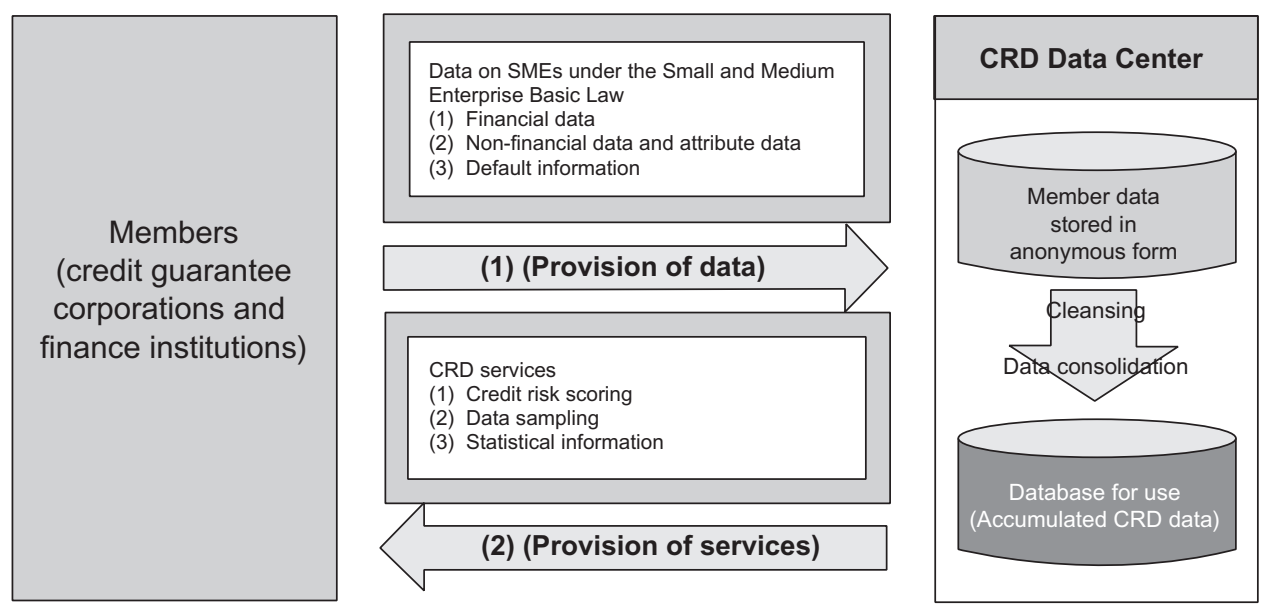

Source: Credit Risk Database of Japan website.

Establishing similar systems in other countries of Asia to accumulate and analyze credit risk data and to measure credit risks of SMEs accurately would enable them to raise funds from the banking sector and give them access to the debt market by securitizing their claims.

Governments throughout Asia could set as a long-term target the development of a centralized SME database. In the interim, there are a variety of accessible databases that could be used for credit rating, such as the financial statements of SME customers held by governmental and private institutions or the extensive database of SMEs at the tax bureaux of the ministries of finance. In fact, data used for credit analysis in section IV of the present paper is for a group of SMEs that are customers of an Iranian bank. 


\section{Hometown investment trust funds}

Given that the financial systems in Asia are dominated by banks, the creation of regional funds (or hometown investment trust funds) ${ }^{2}$ to promote lending to start-up companies and riskier borrowers, such as SMEs, would help maintain the soundness of the banking sector, as banks would not be exposed to the risks that lending to such companies inevitably poses. Selling those regional trust funds through branch offices of regional banks, post offices, credit associations, and large banks would increase funding sources for regional companies.

Such trust funds would not be guaranteed by a deposit insurance corporation and the associated risks would be borne by investors. The terms of a trust fund would have to be fully explained to investors, such as where their funds would be invested and what the risks associated with the investment would be, in order to strengthen potential investors' confidence and help expand the trust fund market (Yoshino, 2013). Examples of such funds in Japan include wind power generators and musicians' funds. In the first example, to construct 20 wind power generators, private-public partnerships were launched with investment of $\$ 1,000-5,000$ by local residents in a fund. They receive dividends every year through the sales of electricity by each wind power generator that they had invested in. Musicians' funds gather many small investors buying units for $\$ 150-500$. If the musicians become successful and their DVDs sell well, the sales generate a high rate of return for the fund.

Examples of both successful and failed funds can be cited. Project assessors play a key role in evaluating each project to limit the number of non-performing investments and losses by investors. Some of the funds set up in Japan are regarded as charities, with some investors viewing them as a way to invest in their region to support new business ventures.

Such new ventures pose a problem for banks, as although some will have high expected rates of return, the high risks involved make it difficult for banks to finance them. However, if the projects are financed by hometown investment trust funds rather than by deposits transformed into bank loans, they will not create non-performing loans for banks. Banks can still benefit and compete with each other by selling the trust funds through their branch offices, although it has to be made clear that an investment in those funds is not guaranteed. If a bank sells successful hometown investment trust funds, it will be able to attract more investors while on the other hand, if it sells loss-making funds, it will lose investors in the future. Competition

\footnotetext{
2 Hometown investment trust funds were only recently established and now have been adopted as a national strategy in Japan (Yoshino and Taghizadeh-Hesary, 2014a).
} 
will improve the quality of projects and enhance the risk-adjusted returns for investors.

Figure 6 shows how trust funds can increase investment in riskier projects.

\section{Figure 6. Bank-based small and medium-sized enterprise financing and hometown investment financing to riskier borrowers}

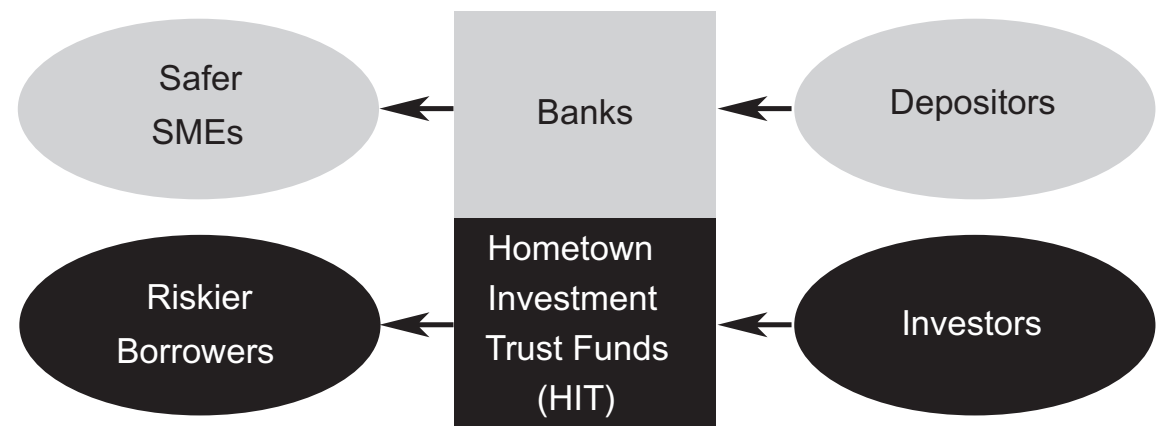

Source: Yoshino and Taghizadeh-Hesary (2015).

A hometown investment trust fund has three main advantages. First, it contributes to financial market stability by lowering information asymmetry. Individual households and firms have direct access to information about the borrowing firms, mainly SMEs. Second, it is a stable source of risk capital. The fund is project driven. Firms and households decide to invest by getting to know the borrowers and their projects. In this way, the fund distributes risk, but not so that it renders risk intractable, which has been the problem with the "originate and distribute" model. Third, it contributes to economic recovery by connecting firms and households with SMEs that are worthy of their support. It also creates employment opportunities at the SMEs as well as for the pool of retirees from financial institutions who can help assess the projects (Yoshino, 2013; Yoshino and Taghizadeh-Hesary, 2014b; 2014c).

\section{ANALYSIS OF SMALL AND MEDIUM-SIZED ENTERPRISE CREDIT RISK USING ASIAN DATA}

In this section an efficient and comprehensive scheme for credit rating of SMEs is presented. Various financial ratios that describe the characteristics of SMEs and enable banks to categorize their SME customers into different groups based on their financial health are examined. This method is also applicable for hometown 
investment trust funds. The data for this statistical analysis were provided by an Iranian bank for 1,363 SMEs.

This method could be also used for credit rating even in the non-SME sector. For a recent study, Yoshino, Taghizadeh-Hesary and Nili (2015) used this method for credit rating and classifying 32 Iranian banks. Based on the results, the banks were classified into two groups and rated based on their soundness.

\section{Selection of the variables}

A number of possible ratios have been identified as useful in predicting a firm's likelihood of default. Chen and Shimerda (1981) show that out of more than 100 financial ratios, almost 50 per cent of them were useful in at least one empirical study. Some scholars have argued that quantitative variables are not sufficient to predict SME default and that including qualitative variables, such as the legal form of the business, the region where the main business is carried out and the industry type, improves the models' predictive power (for example, Lehmann, 2003; Grunert, Norden and Weber, 2004). However, the data used here are based on firm's financial statements, which do not contain such qualitative variables.

For this study, the author's followed Altman and Sabato (2007), who proposed five categories to describe a company's financial profile: liquidity; profitability; leverage; coverage; and activity. For each of those categories, they created a number of financial ratios identified in the literature. Table 1 shows the financial ratios selected for this survey.

In the next stage, two statistical techniques are used: principal component analysis; and cluster analysis. The underlying logic of both techniques is dimension reduction, namely summarizing information on multiple variables into just a few variables, which is achieved in different ways. Principal component analysis reduces the number of variables into components (or factors). Cluster analysis reduces the number of SMEs by placing them in small clusters. In this survey, components (factors) resulting from the principal component analysis are applied and then the cluster analysis is carried out in order to group the SMEs.

\section{Principal component analysis}

Principal component analysis is a standard data reduction technique that entails extracting data, removing redundant information, highlighting hidden features and visualizing the main relationships that exist between observations. ${ }^{3}$ This analysis

3 Principal component analysis is also referred to as the Karhunen-Loève Transform (named after Kari Karhunen and Michel Loève.) 
is a technique for simplifying a data set by reducing multidimensional data sets to lower dimensions for analysis. Unlike other linear transform methods, principal component analysis does not have a fixed set of basis vectors. Its basis vectors depend on the data set. The principal component analysis has the additional advantage of indicating what is similar and different about the various models created (Bruce-Ho and Dash-Wu, 2009). Through this method, the 11 variables listed in table 1 were used to determine the minimum number of components that can account for the correlated variance among SMEs.

Table 1. Examined variable

\begin{tabular}{llll}
\hline No. & \multicolumn{1}{c}{ Symbol } & \multicolumn{1}{c}{ Definition } & Category \\
\hline 1 & Equity_TL & Equity (book value)/total liabilities & Leverage \\
2 & TL_Tassets & Total liabilities/total assets & \\
\hline 3 & Cash_Tassets & Cash/total assets & Liquidity \\
4 & WoC_Tassets & Working capital/total assets & \\
5 & Cash_Sales & Cash/net sales & Profitability \\
\hline 6 & EBIT_Sales & EBIT/sales & \\
7 & Rinc_Tassets & Retained earnings/total assets & Coverage \\
\hline 8 & Ninc_Sales & Net income/sales & Activity \\
\hline 9 & EBIT_IE & EBIT/interest expenses & \\
\hline 10 & AP_Sales & Account payable/sales & Account receivable/total liabilities \\
\hline
\end{tabular}

Notes: Retained earnings = the percentage of net earnings not paid out as dividends, but retained by the company to be reinvested in its core business or to pay debt. It is recorded under shareholders' equity in the balance sheet. EBIT = earnings before interest and taxes. Account payable = an accounting entry that represents an entity's obligation to pay off a short-term debt to its creditors. The accounts payable entry is found on a balance sheet under current liabilities. Account receivable = money owed by customers (individuals or corporations) to another entity in exchange for goods or services that have been delivered or used, but not yet paid for. Receivables usually come in the form of operating lines of credit and are usually due within a relatively short time period, ranging from a few days to a year.

In order to examine the suitability of these data for factor analysis, the KaiserMeyer-Olkin (KMO) test and Bartlett's test of sphericity were performed. KMO is a measure of sampling adequacy that indicates the proportion of common variance that might be caused by underlying factors. High KMO values (larger than 0.60) generally indicate that factor analysis may be useful, which is the case in this study: $\mathrm{KMO}=0.71$. If the $\mathrm{KMO}$ value is less than 0.5 , factor analysis would not be useful. Bartlett's test of sphericity indicates whether the correlation matrix is an identity 
matrix, indicating that variables are unrelated. A significance level less than 0.05 indicates that there are significant relationships among the variables, which is the case in this study: significance of Bartlett's test $<0.001$.

Next, the number of factors to be used in the analysis was determined. Table 2 reports the estimated factors and their eigenvalues. Only those factors accounting for more than 10 per cent of the variance (eigenvalues $>1$ ) were kept in the analysis. As a result, only the first four factors were finally retained (table 2).

Taken together, Z1 through Z4 explain 71.06 per cent of the total variance of the financial ratios.

Table 2. Total variance explained

\begin{tabular}{cccc}
\hline Component & Eigenvalues & \% of variance & Cumulative variance \% \\
\hline Z1 & 3.30 & 30.00 & 30.00 \\
Z2 & $\mathbf{2 . 1 9}$ & 19.90 & 49.90 \\
Z3 & $\mathbf{1 . 2 5}$ & $\mathbf{1 1 . 3 8}$ & 61.28 \\
Z5 & $\mathbf{1 . 0 8}$ & 9.78 & $\mathbf{7 1 . 0 6}$ \\
Z6 & 0.94 & 8.56 & 79.62 \\
Z7 & 0.75 & 6.79 & 86.41 \\
Z8 & 0.56 & 5.09 & 91.50 \\
Z9 & 0.48 & 4.36 & 95.86 \\
Z10 & 0.32 & 2.87 & 98.73 \\
Z11 & 0.13 & 1.14 & 99.87 \\
\hline
\end{tabular}

To run the principal component analysis, the direct oblimin rotation was used. Direct oblimin is the standard method to obtain a non-orthogonal (oblique) solution that is, one in which the factors are allowed to be correlated. In order to interpret the revealed principal component analysis information, the pattern matrix must then be studied. Table 3 presents the pattern matrix of factor loadings by use of the direct oblimin rotation method in which variables with large loadings, absolute value $(>0.5)$ for a given factor, are highlighted in bold. 
Table 3. Factor loadings of financial variables after direct oblimin rotation

\begin{tabular}{lcccc}
\hline \multirow{2}{*}{$\begin{array}{c}\text { Variables } \\
\text { (financial ratios) }\end{array}$} & \multicolumn{4}{c}{ Component } \\
\cline { 2 - 5 } Equity_TL & $\mathbf{Z 1}$ & $\mathbf{Z 2}$ & $\mathbf{Z 3}$ & $\mathbf{Z 4}$ \\
TL_Tassets & 0.009 & 0.068 & 0.113 & $\mathbf{0 . 7 0 5}$ \\
Cash_Tassets & -0.032 & -0.878 & 0.069 & -0.034 \\
WoC_Tassets & -0.034 & -0.061 & $\mathbf{0 . 8 1 1}$ & 0.098 \\
Cash_Sales & -0.05 & $\mathbf{0 . 7 6 2}$ & 0.044 & 0.179 \\
EBIT_Sales & $-\mathbf{0 . 9 3 7}$ & 0.021 & 0.083 & 0.009 \\
Rinc_Tassets & $\mathbf{0 . 9 6 2}$ & 0.008 & 0.024 & -0.004 \\
Ninc_Sales & 0.014 & $\mathbf{0 . 8 7 7}$ & 0.015 & -0.178 \\
EBIT_IE & $\mathbf{0 . 9 7 1}$ & -0.012 & 0.015 & 0.014 \\
AP_Sales & 0.035 & 0.045 & $\mathbf{0 . 7 6 6}$ & -0.098 \\
AR_TL & $-\mathbf{0 . 7 3 1}$ & -0.017 & -0.037 & -0.016 \\
\hline
\end{tabular}

Note: The extraction method was principal component analysis. The rotation method was direct oblimin with Kaiser normalization.

As evident in table 3 , the first component, Z1, has four variables with an absolute value (>0.5), of which two are positive (EBIT/sales and net income/sales) and two are negative (cash/net sales and account payable/sales). For Z1, the variables with large loadings are mainly net income and earnings, hence, Z1 generally reflects the net income of an SME. As this factor explains the most variance in the data, it is the most informative indicator of the overall financial health of an SME. Z2 reflects short-term assets. This component has three major loading variables: (a) liabilities/total assets which is negative and means an SME has few liabilities and mainly relies on its own assets; (b) working capital/total assets which is positive and, means an SME has short-term assets; (c) retained earnings/total assets, which is positive and means an SME has earnings, which it reinvests in the company. These three variables indicate an SME that has small borrowing and sizeable working capital and retained earnings, and therefore, has plenty of short-term assets. Z3 reflects the liquidity of SMEs. This factor has two variables with large loadings (cash/total assets and EBIT/interest expenses), both with positive values, which shows an SME that is cash-rich and has high earnings, hence, it mainly reflects the liquidity conditions of an SME. The last factor, Z4, reflects capital. It has two variables with large loading, both with positive values, equity (book value)/total liabilities and account receivable/total liabilities and indicates an SME with few liabilities that has sizeable equity. 
Table 4 shows the correlation matrix of the components. It indicates that there is no correlation between these four components. This means a regular orthogonal rotation approach could have been used to force an orthogonal rotation. In this survey, an oblique rotation method is used. This method still provides basically an orthogonal rotation factor solution because these four components are not correlated with each other and are distinct entities.

Table 4. Component correlation matrix

\begin{tabular}{cllll}
\hline Component & Z1 & Z2 & Z3 & Z4 \\
\hline Z1 & 1.00 & 0.037 & -0.031 & -0.005 \\
Z2 & 0.037 & 1.00 & 0.106 & 0.102 \\
Z3 & -0.031 & 0.106 & 1.00 & 0.033 \\
Z4 & -0.005 & 0.102 & 0.033 & 1.00 \\
\hline Note: & \multicolumn{4}{l}{ The extraction method is principal component analysis. The rotation method is direct } \\
& oblimin with Kaiser Normalization.
\end{tabular}

Figure 7 shows the distribution of the four components (Z1, Z2, Z3, and Z4) for group A, financially sound SMEs, and group B, non-sound SMEs.

It is clear from the six graphs in this figure that group A (sound) SMEs can generally be found in the positive areas of the graphs and group B SMEs in the negative areas, or in inferior places in most cases when compared to the sound group. This shows that these four defined components (Z1, Z2, Z3, and Z4) are able to separate SMEs. It means that these components could be a good measure for showing the financial healthiness of SMEs.

\section{Cluster analysis}

In this section, the four components that were obtained in the previous section are reviewed to identify SMEs that have similar traits. Clusters were then generated and SMEs were placed in distinct groups. To do this, cluster analysis is undertaken. In cluster analysis, a set of data is organized into groups so that observations from a group with similar characteristics can be compared with those from a different group (Martinez and Martinez, 2005). In this case, SMEs were organized into distinct groups according to the four components derived from the principal component analysis used in the previous section. Cluster analysis techniques can themselves be broadly grouped into three classes: hierarchical clustering, optimization 
Figure 7. Distribution of factors for groups A and B of small and medium-sized enterprises
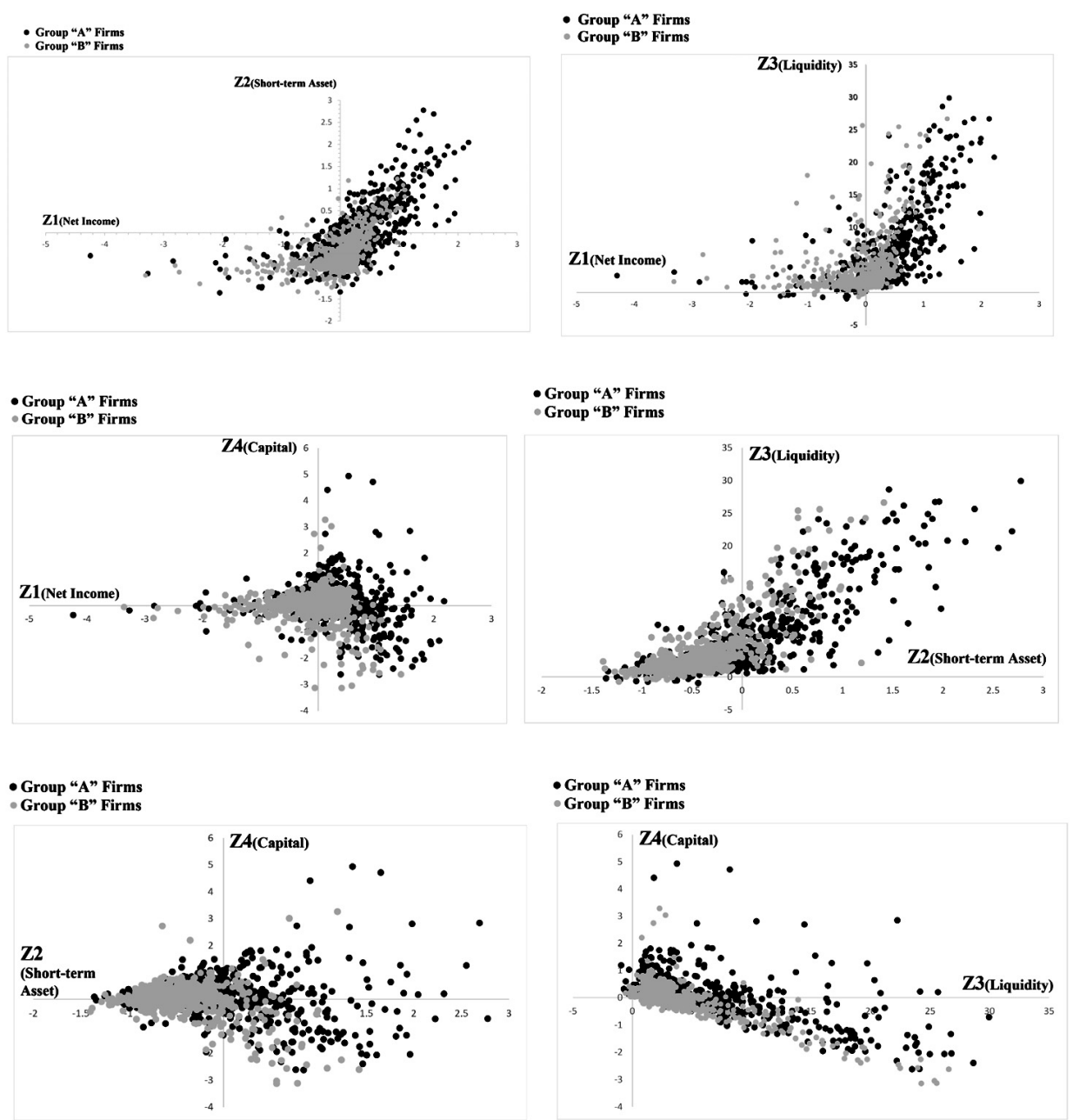

Notes: $\quad$ Group A = sound SMEs, group B = non-sound SMEs. The firms considered to be non-sound in this study have risk-weighted assets greater than their shareholders' equity. 
clustering, ${ }^{4}$ and model-based clustering. For this study, the most prevalent method in the literature, hierarchical clustering was used. This produces a nested sequence of partitions by merging (or dividing) clusters. At each stage of the sequence, a new partition is optimally merged (or divided) from the previous partition according to some adequacy criterion. The sequence of partitions ranges from a single cluster containing all the individuals to a number of clusters $(n)$ containing a single individual. The series can be described by a tree display called the dendrogram (figure 8). Agglomerative hierarchical clustering proceeds by a series of successive fusions of the $n$ objects into groups. By contrast, divisive hierarchical methods divide the $n$ individuals into progressively finer groups. Divisive methods are not commonly used because of the computational problems they pose, see Everitt, Landau and Leese (2001) and Landau and Chis Ster (2010). Below, the average linkage method, which is a hierarchical clustering technique, is used.

\section{The average linkage method}

The average linkage (AL) method defines the distance between clusters as the average distance from all observations in one cluster to all points in another cluster. In other words, it is the average distance between pairs of observations, where one is from one cluster and one is from the other. The average linkage method is relatively robust and also takes the cluster structure into account (Martinez and Martinez, 2005; Feger and Asafu-Adjaye, 2014). The basic algorithm for the AL method can be summarized in the following manner:

- $\quad N$ observations start out as $N$ separate groups. The distance matrix $D=$ (dij) is searched to find the closest observations, for example, $\mathrm{Y}$ and $\mathrm{Z}$.

- The two closest observations are merged into one group to form a cluster (YZ), producing $N-1$ total groups. This process continues until all the observations are merged into one large group.

Figure 8 shows the dendrogram that results from this hierarchical clustering.

\footnotetext{
4 The main difference between the hierarchical and optimization techniques is that in hierarchical clustering, the number of clusters is not known beforehand. The process consists of a sequence of steps during which two groups are either merged (agglomerative) or divided (divisive) according to the level of similarity. Eventually, each cluster can be subsumed as a member of a larger cluster at a higher level of similarity. The hierarchical merging process is repeated until all subgroups are fused into a single cluster (Martinez and Martinez, 2005). Optimization methods on the other hand do not necessarily form hierarchical classifications of the data as they produce a partition of the data into a specified or predetermined number of groups by either minimizing or maximizing some numerical criterion (Feger and Asafu-Adjaye, 2014).
} 
Figure 8. Dendrogram using average linkage

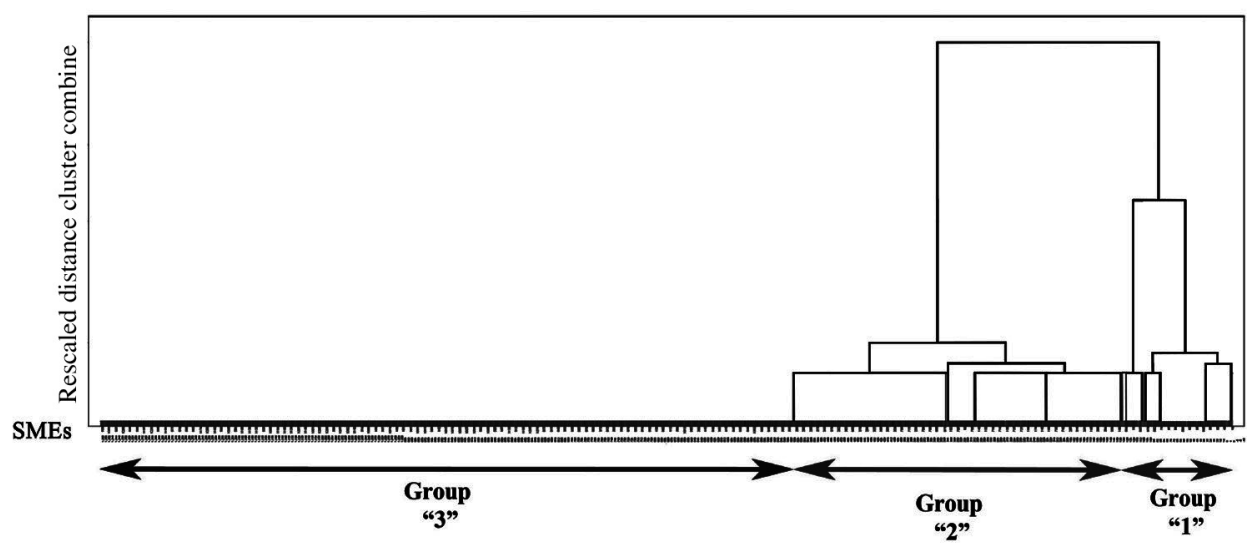

The resultant dendrogram (hierarchical average linkage cluster tree) provides a basis for determining the number of clusters by sight. In the dendrograms shown in figure 8, the horizontal axis shows 1,363 SMEs. Owing to their large number, SMEs have not been identified by number in the dendrogram, although this is how SMEs are identified in this survey. Rather, the dendrogram categorizes the SMEs in three main clusters (groups 1, 2, and 3), but it does not show which of those three clusters contain the financially healthy SMEs, which contains least healthy or risky SMEs, and which contain intermediate SMEs, hence, there is one more step to go.

Figure 8 shows the 1,363 SMEs categorized into three major clusters. Using their components, which were derived from the principal component analysis, the distribution of factors for each member of the three major clusters can be plotted. Figure 9 shows the distribution of Z1-Z2 for these three cluster members separately. ${ }^{5}$

The dendrogram shows us the major and minor clusters. One of useful features of this tree is that it identifies a representative SME of most of the minor groups, which has the average traits of the other members of the group. Hence for simplification, in figure 9, there is only used data from these representative SMEs, which explains the whole group's traits. This is why the total number of observations in figure 9 is lower than the 1,363 observations in this survey. 
Figure 9. Grouping based on principal component analysis (Z1-Z2) and cluster analysis

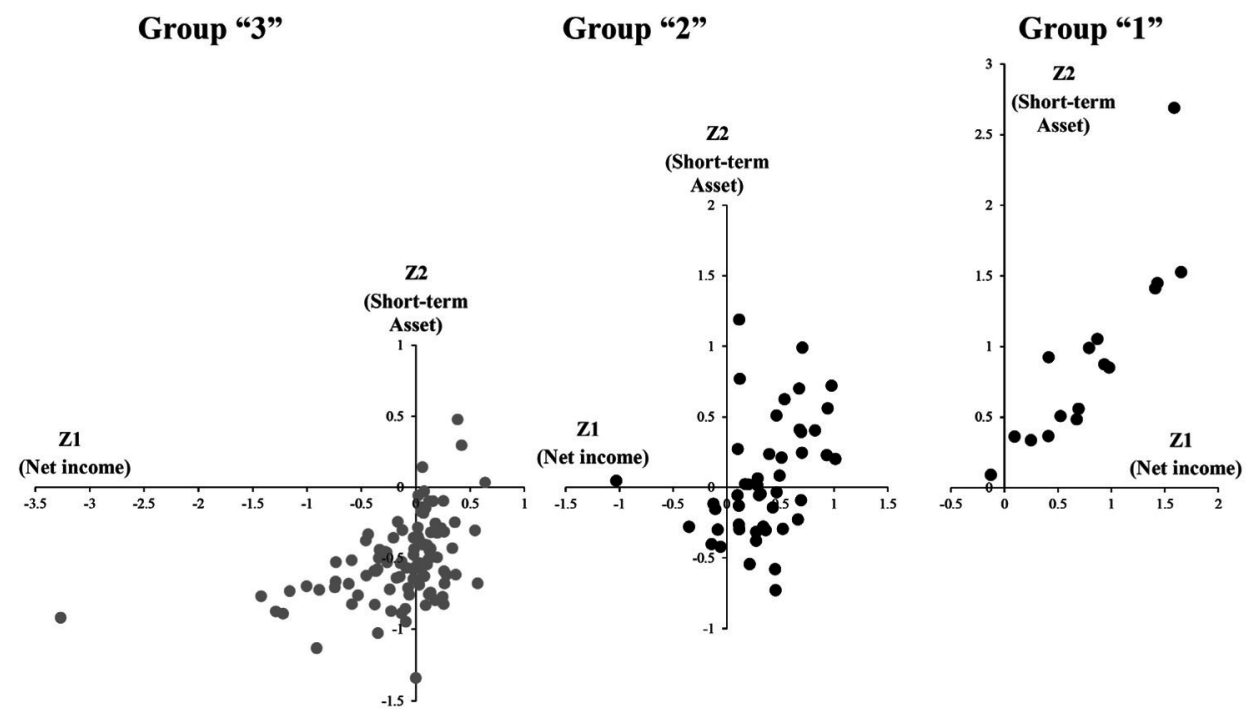

Note: $\quad$ Group 1 = healthiest SMEs; group 2 = in-between SMEs; group 3 = least healthy SMEs.

As indicated in figure 9, group 1 consists of the healthest SMEs, group 3 contains the SMEs with the lowest healthiness and group 2 are those that are in-between. Interestingly, when this grouping is carried out by using the other components (Z1-Z3, Z1-Z4, Z2-Z4, Z2-Z3, and Z3-Z4), in most cases, the grouping is similar. This implies that this analysis is an effective way of grouping SMEs.

\section{CONCLUDING REMARKS}

SMEs play a significant role in Asian economies as they are responsible for very high shares of employment and output in all Asian countries. However, they have limited access to finance compared to large enterprises. Banks dominate the financial systems in Asia and as a consequence are the main source of financing for SMEs. Besides banks, the creation of regional funds (or hometown investment trust funds) to promote lending to riskier customers, such as SMEs, would be the second choice of financing. 
For financial institutions, it is crucial to recognize healthy SMEs from the non-healthy SMEs, in order to avoid accumulation of non-performing loans. This is possible by applying statistical analysis techniques on financial variables of SMEs.

In this research, 11 financial variables of 1,363 SMEs that are customers of an Asian bank are used for the analysis. These variables are subjected to principal component analysis and cluster analysis. The results showed that four variables (net income, short-term assets, liquidity and capital) are the most important for describing the general characteristics of SMEs. Three groups of SMEs were then differentiated based on the financial health of those 1,363 SMEs.

The policy implications of this paper are that it is crucial for the governments to collect SME data and prepare a rich database, such as the Credit Risk Database of Japan. This will help governments formulate economic policies and facilitate a path towards developing an efficient credit rating mechanism. Since establishing a credit risk database takes time, in the short-run, governmental or private financial institutions could apply similar credit rating techniques on SME customers' balance sheet information, and recognize healthy SMEs. Under such a scenario: (a) financially healthy SMEs could borrow much more money from banks at lower interest rates because of their lower default risk; (b) SMEs in poor financial health would have to pay higher interest rates on their borrowing from the financial institutions and have a lower borrowing ceiling than healthy SMEs; and (c) banks could reduce the amount of their accumulated non-performing loans to SMEs. Also of note, if the hometown investment trust funds were to be sold through regional banks, post offices, credit associations, or even large banks, these financial institutions could apply the aforementioned credit rating analysis, and decide on the closure or continuing of such funds. 


\section{REFERENCES}

Altman, E.I., and G. Sabato (2007). Modelling credit risk for SMEs: evidence from the U.S. market. ABACUS, vol. 43, No. 3, pp. 332-357.

Asian Development Bank (ADB) (2014). Asia SME Finance Monitor 2013. Manila.

Bank of Japan (2014). Tankan 2014: short-term economic survey of enterprises in Japan. Tokyo: Research and Statistics Department.

Bruce-Ho, C.-T., and D. Dash-Wu (2009). Online banking performance evaluation using data envelopment analysis and principal component analysis. Computers \& Operations Research, vol. 36, pp. 1835-1842.

Chen, K.H., and T.A. Shimerda (1981). An empirical analysis of useful financial ratios. Financial Management, vol. 10, No. 1, pp. 51-60.

Everitt, B.S., S. Landau, and M. Leese (2001). Cluster Analysis, 4 ed. London: Arnold.

Feger, T., and J. Asafu-Adjaye (2014). Tax effort performance in Sub-Sahara Africa and the role of colonialism. Economic Modelling, vol. 38, pp. 163-174.

Grunert, J., L. Norden, and M. Weber (2004). The role of non-financial factors in internal credit ratings. Journal of Banking and Finance, vol. 29, No. 2, pp. 509-531.

Landau, S., and I. Chis Ster (2010). Cluster analysis: overview. International Encyclopedia of Education, 3 ed. Oxford: Elsevier.

Lehmann, B. (2003). Is it worth the while? The relevance of qualitative information in credit rating. Working paper presented at the European Financial Management Association 2003 Annual Meetings. Helsinki, 25-28 June.

Martinez, W.L., and A.R. Martinez (2005). Exploratory Data Analysis with Matlab. Florida: Chapman and Hall/CRC Press.

Yoshino, N. (2012). Global imbalances and the development of capital flows among Asian countries. OECD Journal: Financial Market Trends, vol. 2012, No. 1, pp. 81-112.

(2013). The background of hometown investment trust funds. In Hometown Investment Trust Funds: A Stable Way to Supply Risk Capital, N. Yoshino and S. Kaji, eds. Tokyo: Springer.

Yoshino, N., and F. Taghizadeh-Hesary (2014a). Hometown investment trust funds: an analysis of credit risk. Paper presented at the Executive Secretary's Seminar Series on Financing for Sustainable Development: Local and Global Perspectives. United Nations Economic and Social Commission for Asia and the Pacific. Bangkok, 31 October.

(2014b). Hometown investment trust funds: an analysis of credit risk. Working Paper, No. 505. Tokyo: Asian Development Bank Institute.

(2014c). Three arrows of "Abenomics" and the structural reform of Japan: inflation targeting policy of the Central Bank, fiscal consolidation, and growth strategy. Working Paper, No. 492. Tokyo: Asian Development Bank Institute.

(2015). An analysis of challenges faced by Japan's economy and Abenomics. Japanese Political Economy Journal, vol. 40, pp. 1-26, DOI: 10.1080/2329194X.2014.998591.

Yoshino, N., F. Taghizadeh Hesary, and F. Nili (2015). Estimating dual deposit insurance premium rates and forecasting non-performing loans: two new models. Working Paper, No. 510. Tokyo: Asian Development Bank Institute. 
